\title{
A NOTE ON ENKABANG AND TEGLAM FATS AND KATIO OIL FROM SARAWAK.
}

By CECIL J. BROOKS, F.I.C.

(Read at the Meeting, April 7, 1909.)

Enkabang Fat is obtained from the fruit of a large jungle tree, Shorea Ghysbertiana, belonging to the order of Dipterocarps. Locally the seeds are known as Enkabang Jantong, but in the Singapore market as Sengkawang, which name includes the three varieties of exported Enkabang. The tree is of wide distribution in the country, growing freely in all lowland jungle, where it has no doubt been cultivated to a certain extent by the Dyaks, as the seeds find a ready market in Singapore, a considerable quantity being exported during a good fruit season. The fruit is a large, nearly oval nut, measuring about $1 \frac{3}{4}$ inches in length, and having, when airdried, an average weight of 13 grams. The shell is fairly tough, but easily removed.

The market value is as much as $\$ 5$ per picul ( $133 \frac{1}{3}$ pounds) in Kuching bazaar. The tree, however, is not a regular bearer; long intervals may at times elapse between its fruiting periods. This, unfortunately, would form a serions drawback to its commercial cultivation.

The quantity of seeds exported in 1903 was 11,764 piculs. There was no special export until 1908, when 39,216 piculs left the country; this points to the fruit season only occurring once in three or five years. The seeds are exported as the husked kernel, sun-dried, both Enkabang and Teglam mixed. There is a similar seed containing no oil which the Chinaman buys and mixes with these. A European firm should purchase on the basis of "oil content."

The natives extract the fat by heat and pressure, and esteem it a valuable article 
of diet. The fat content is high, amounting to 31.2 per cent. on the nut and 46.7 per cent. on the kernel, when air-dried. A sample of fat of Dyak make had a slight odour, somewhat resembling tallow, and a slight but agreeable taste. The colour of the solid is yellow-grey, which on melting becomes golden-yellow. A section of the fat showed that the solidification had taken place in nodular masses, clearly defined by white lines.

On examination the following figures were obtained:

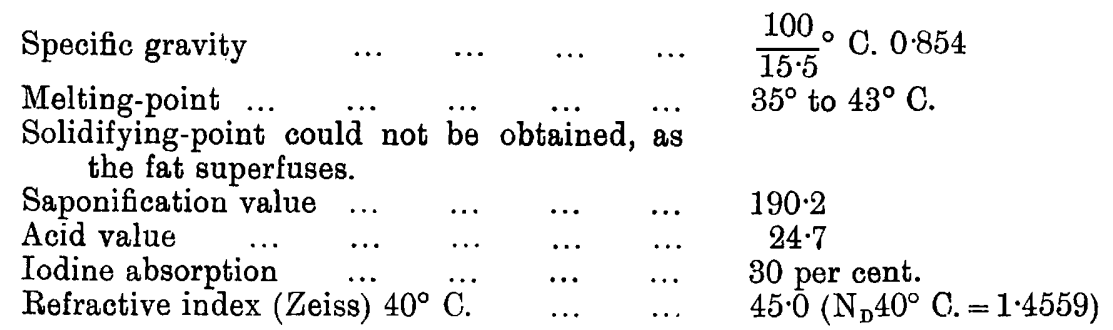

A sample of the fat was prepared by extracting the seeds with carbon disulphide. After carefully removing the solvent from the fat, it had a slightly rancid odour, an unpleasant taste, and a yellow colour, which rapidly bleached to white on exposure to light; when melted the colour was bright yellow.

The following analytical data were obtained:

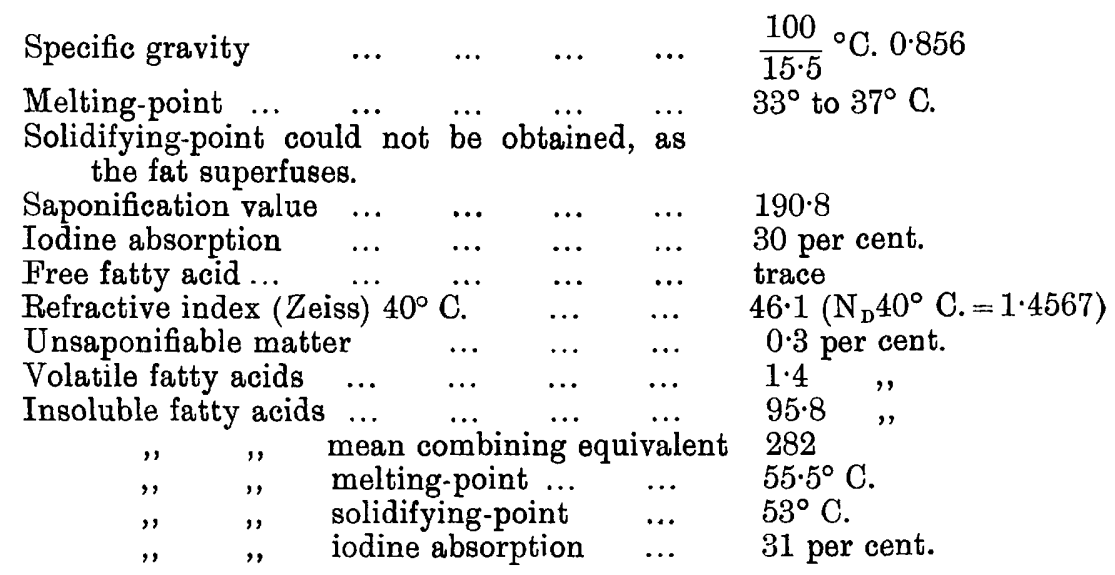

Teglam Fat closely resembles Enkabang fat in its occurrence, etc. It is obtained from the seeds of Isoptera Borneensis, also a member of the order of Dipterocarps. The seeds are similar in shape, but smaller in size. They are known locally as Enkabang Changi. The fat for edible purposes is considered superior to any other, as it will keep in good condition for a number of years.

A sample of the fat of Dyak preparation had a pale yellow-green colour, when fused was yellow, with a tinge of green; the solidified fat, when exposed in section, exhibited a solid structure, with bere and there white nuclei. It has a sweet buttery taste and slight odour. 
On examination the following analytical data were obtained :

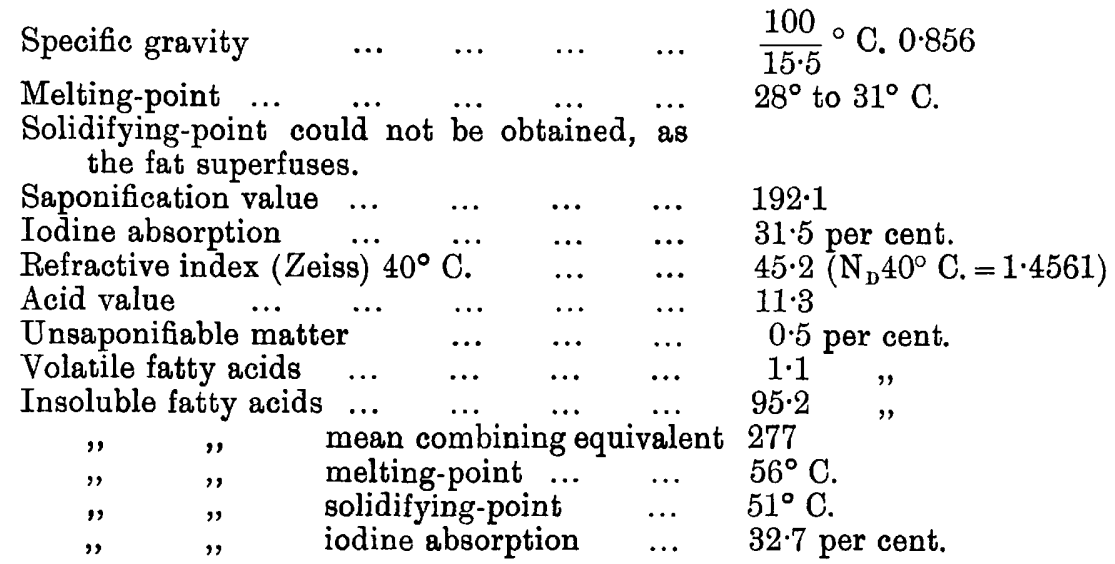

Katio or Kachiau Oil is obtained from the seeds of a species of Bassia, of the order Sapotaceæ. The tree grows in abundance in the swamps of the Sadong and Saribas districts. At present it has no commercial value, although highly prized by the natives for cooking and other food purposes. The small, oval, brown seeds, when air-dried, have an average weight of 0.391 gram, and contain 40 per cent. of oil. After the removal of the thin crisp shell the kernels gave 47.5 per cent. of oil. A sample of Dyak prepared oil had a bright yellow colour, a sweet taste, and a pleasant odour of almonds. The oil is non-drying.

The following analytical data were obtained:

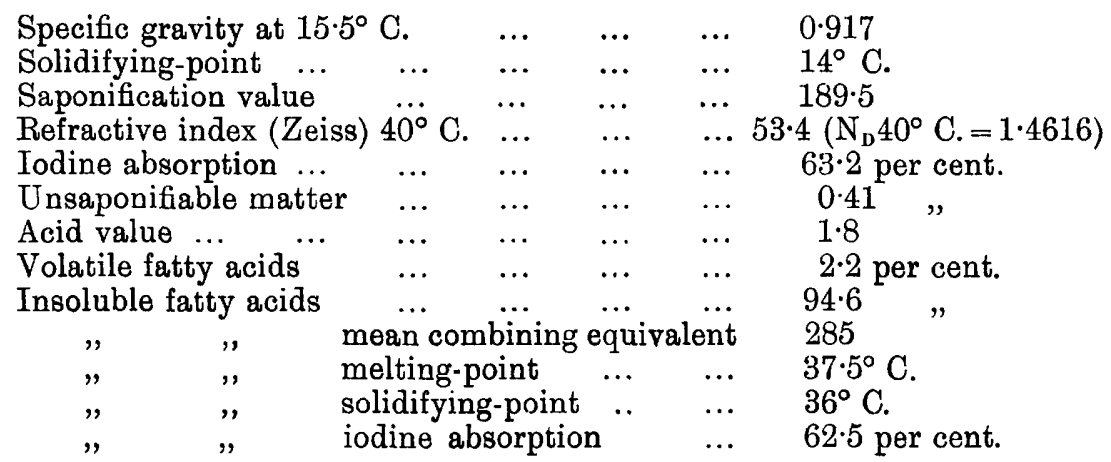

Elä̈din Test.-The mass after one hour could not be displaced by shaking the bottle; after twelve hours the mass had the consistency of a soft American cheese.

In conclusion, I wish to tender my thanks to Mr. John Hewitt, of the Sarawak Museum, for kindly providing me with samples and botanical notes; and to Mr. E. R. Bolton, for determining the refractive indices recorded in this paper.

\section{Discussion.}

Mr. L. Myddelton Nash (by whom the paper was communicated), in reply to a question put by the President, said that, so far as he knew, these fats had not yet 
been exported to this country, but he understood that some interest was being taken in them from the point of view of their use for edible purposes, and it was possible that they might shortly be introduced. Unfortunately, however, as Mr. Brooks had remarked in the paper, the tree did not bear fruit every year, but only at intervals of from three to five years, so that the supply probably would not be regular.

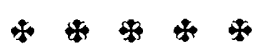

